\title{
Editorial for the Special Edition on Contributions to Asia Oceania Atmospheric Sciences
}

In 2014, the JMSJ Editorial Committee proposed a special edition comprising papers presented at 11th Annual Meeting of the Asia Oceania Geosciences Society (AOGS2014), which was held in Sapporo, Japan, from 28 July to 1 August 2014. The journal issued an open call for submissions based on papers presented in the Atmospheric Sciences section of AOGS2014. The Editorial Committee assessed manuscripts submitted before the March 2015 deadline, and accepted five papers for publication in the Special Edition on Contributions to Asia Oceania Atmospheric Sciences. Unlike previous JMSJ Special Editions that were each published in a single issue, the papers of this edition were published separately in journal issues as they were accepted. They are presented as a virtual collection online: http://jmsj.metsoc.jp/ special_issues_editions/vol93no4.html.

The papers in this Special Edition describe important contributions to researches of atmospheric sciences. Satoh et al. (2015) discuss constraints on future changes in the global frequency of tropical cyclones. This paper was one of two recipients of the JMSJ Award in 2015. Seiki et al. (2015) examine the relationships between sea surface temperature cooling in the southeastern Indian Ocean, oceanic Rossby waves and the seasonal onset of the MaddenJulian oscillation from 1993 to 2012. This paper was also part of the Special Issue on the Coordinated International Field Campaign on the Madden-Julian Oscillation (Vol. 93A). Using reanalysis data and chemistry climate model simulations, Yamashita et al. (2015) investigate the combined influences of the westerly phase of the quasi-biennial oscillation and solar maximum conditions on the Northern Hemisphere extratropical winter circulation. Romanskiy and Verbitskaya (2016) investigate the 2013 flood of the Amur River in China and Russia using operational numerical simulations of prolonged precipitation. Suwarman et al. (2017) show the response of stable isotopes in precipitation to El Niño-Southern Oscillation events and the spatial distribution of water sources from a particular region.

The Special Edition on Contributions to Asia Oceania Atmospheric Sciences provided a valuable opportunity for publishing papers to the presenters at AOGS2014, and is a vital addition to the body of work on atmospheric research. On behalf of the JMSJ Editorial Committee, I thank the authors for their contributions and invite readers to make full use of this collection. 


\section{References}

Romanskiy, S., and E. Verbitskaya, 2016: The 2013 Amur River flood: Operational numerical simulation of prolonged precipitation. J. Meteor. Soc. Japan, 94, 137-150.

Satoh, M., Y. Yamada, M. Sugi, C. Kodama, and A. T. Noda, 2015: Constraint on future change in global frequency of tropical cyclones due to global warming. J. Meteor. Soc. Japan, 93, 489-500.

Seiki, A., M. Nagura, T. Hasegawa, and K. Yoneyama, 2015: Seasonal onset of the Madden-Julian Oscillation and its relation to the southeastern Indian Ocean cooling. J. Meteor. Soc. Japan, 93A, 139-156.

Suwarman, R., K. Ichiyanagi, M. Tanoue, K. Yoshimura, S. Mori, M. D. Yamanaka, F. Syamsudin, and H. A. Belgaman, 2017: El Niño Southern Oscillation signature in atmospheric water isotopes over Maritime Continent during wet season. J. Meteor. Soc. Japan, 95, 49-66.

Yamashita, Y., H. Akiyoshi, T. G. Shepherd, and M. Takahashi, 2015: The combined influences of westerly phase of the Quasi-Biennial Oscillation and 11-year solar maximum conditions on the Northern Hemisphere extratropical winter circulation. J. Meteor. Soc. Japan, 93, 629-644. 